\title{
Contribuição para o Ensino de Ciências por meio de uma atividade experimental de condutividade térmica
}

\author{
Sabrina Passoni \\ Nadiangela Mayer \\ Jeremias Borges da Silva \\ André Maurício Brinatti \\ Silvio Luiz Rutz da Silva
}

\begin{abstract}
Resumo
O ensino e aprendizagem ao serem conduzidos por meio da problematização, direcionada e inserida em um tema de interesse proporciona diversos caminhos para a construção do conhecimento dos estudantes. Em um ambiente dinâmico e de diálogo deparou-se com questões levantadas pelos próprios estudantes, que abrangem diversos conceitos inseridos no tema: isolantes e condutores térmicos. Estes questionamentos puderam ser compreendidos, por meio de uma atividade experimental que teve como objetivo principal medir condução de calor em diferentes tipos de materiais: tanto isolantes quanto condutores. Pretendeu-se conduzir o aluno a investigar e construir o conhecimento a partir da elaboração de hipóteses, de modo a encontrar respostas a seus questionamentos utilizando-se da linguagem científica tendo por base as ideias de Paulo Freire, de Ausubel e de Moreira, e assim, os alunos utilizassem seus conhecimentos prévios de modo a estabelecer uma relação com sua realidade e com seus interesses.
\end{abstract}

Palavras-chave: Problematização, atividade experimental, condutores e isolantes térmicos.

\footnotetext{
Abstract

Contribution to science education through an experimental activity about thermal conductivity

Teaching and learning were driven through the questioning, directed and inserted into a topic of student interest provide various ways for the construction of knowledge these students. In a dynamic environment and dialogue was faced
} 
with issues raised by the students themselves, covering several concepts included in the theme: insulators and thermal conductors. These questions could be understood through an experimental activity that aimed to measure heat conduction in different types of materials: insulating both as drivers. It was intended to lead students to investigate and construct knowledge from the formulation of hypotheses in order to find answers to their questions using the scientific language based on the ideas of Paulo Freire, Ausubel and Moreira, enabled students use their prior knowledge in order to establish a relationship with their reality and their interests.

Keywords: Problematization, experimental activity, conductors and insulating materials.

\section{Introdução}

A melhoria do ensino e aprendizagem de Ciências Naturais nas escolas tem sido foco de estudos em um número crescente trabalhos, principalmente no que diz respeito às disciplinas de física, química e biologia no ensino médio (Rosa, 1999; Espínola e Moreira, 2006; de Souza, Gregorio-Hetem e Ammon, 2009; Krummenauer, da Costa e da Silveira, 2010; Nascimento e Rezende Junior, 2010). Além disso, muitos teóricos da educação vêm ao longo dos anos contribuindo com estudos que orientam os educadores em diferentes horizontes para concretizar de maneira significativa o ensino aprendizagem (Moreira, 1995).

Segundo o construtivista Ausubel (1968) a aprendizagem cognitiva ou simplesmente, significativa, ocorre de forma verbal e receptiva, pois a linguagem é um importante facilitador na evolução do conhecimento já armazenado pelo aluno e o mecanismo de receber novas informações, esta condicionada com a maneira em que são apresentados novos conhecimentos a serem armazenados. Para Ausubel (1968, p. 137) “... o fator isolado mais importante que influencia a aprendizagem é aquilo que o aluno já sabe; descubra isso e ensine-o de acordo...".

De acordo com Moreira (2010), além de Ausubel muitos autores reconhecidos, dentre os quais Paulo Freire, defendem a importância do conhecimento prévio:

"as ideias de Paulo Freire vão até o mais íntimo da sala de aula; os professores preparam suas aulas levando em conta o que os alunos já sabem; eles não são mais elementos vazios, tornam-se um ponto de partida de toda a aprendizagem; os exemplos, os problemas, a finalidade da aprendizagem nascem do que é o aluno concreto". (Almeida, 2009, p. $82^{1}$ apud Moreira, 2010, p. 8, grifo do autor)

${ }^{1}$ Almeida, F. J.. Paulo Freire. Folha Explica. v. 81. São Paulo: Publifolha, 2009. 95p. 
Freire em seu livro Pedagogia do Oprimido (1987) nos coloca que é possível ensinar por meio do diálogo desde que todos construam o que lhes foi apresentado em conjunto, pois não existe a ação da construção do novo conhecimento a ser adquirido sem que ocorra a discussão e ordenação deste:

"Para o educador- educando, dialógico, problematizador, o conteúdo programático da educação não é uma doação ou uma imposição - o conjunto de informes a ser depositado nos educandos - mas a evolução organizada, sistematizada e acrescentada ao povo daqueles elementos que este the entregou de forma desestruturada." (Freire, 1987 p. 98)

Para Moreira (2010) a interação social é indispensável para a concretização de um episódio de ensino e isto ocorre quando se compartilham significados que resultam da negociação que deve envolver uma permanente troca de perguntas ao invés de respostas. A aprendizagem centrada na interação com ênfase no intercambio de perguntas tende a ser critica: "uma vez que se aprende a formular perguntas -- relevantes, apropriadas e substantivas -- aprende-se a aprender e ninguém mais pode impedir-nos de aprendermos o que quisermos" (Potsman \& Weingartner, 1969, p. $23^{1}$ apud Moreira, 2010, p. 9).

Moreira cita que Freire dizia: "... o fundamental é que professor e alunos tenham uma postura dialógica, aberta, curiosa, indagadora e não apassivada, enquanto falam ou ouvem. $O$ que importa é que professor e alunos se assumam epistemologicamente curiosos". (Freire, 2003, p. $86^{2}$ apud Moreira, 2010, p. 9). Ainda segundo Moreira (2010, p. 9) "essa curiosidade epistemológica é, para ele, atingida criticizando a curiosidade ingênua - a das crianças e do senso comum - de modo a aproximar-se cada vez mais metódica e rigorosamente do objeto cognoscível."

Tais elementos nos conduzem a importância da interpretação pessoal e do questionamento entendidos como a capacidade de representar o mundo por meio dos conhecimentos adquiridos o que segundo Moreira (2010) implica na percepção crítica deste mundo: "aquela que permite ao sujeito fazer parte de sua cultura e ao mesmo tempo, estar fora dela." (ibid p. 7)

Moreira (2010, p.12) refere-se à Ciência como uma extensão, um refinamento, da habilidade humana de perceber o mundo. Para ele aprendê-la implica aprender sua linguagem e, em consequência, falar e pensar diferentemente sobre o mundo. Aprendê-la de maneira crítica é perceber essa nova linguagem como uma nova maneira de perceber o mundo.

${ }^{1}$ Postman, N. \& Weingartner, C.. Teaching as a subversive activity. New York, Dell Publishing Co. 1969. 219p.

${ }^{2}$ Freire, P.. Pedagogia da autonomia. 27ed. São Paulo, Paz e Terra. 2003. 148p. 
Quando inserimos a problematização em atividades experimentais, essa pode ter início partindo do educador como também partir do educando. Neste último, o aluno poderá formular questões que já estão previamente construídas, advindas de seu conhecimento prévio, resultado de sua experiência vivida. Entretanto segundo Ferrari (2008, cap.1 p. 11-12), para Delizoicov e Angotti a problematização pode acontecer devido o interesse dos estudantes em investigar uma situação buscando novos conhecimentos:

"A problematização poderá ocorrer pelo menos em dois sentidos. De um lado, pode ser que o aluno já tenha noções sobre as questões colocadas, fruto da sua aprendizagem anterior, na escola ou fora dela. Suas noções poderão estar ou não de acordo com as teorias e as explicações das Ciências, caracterizando o que se tem chamado de "concepções alternativas" ou "conceitos intuitivos" dos alunos. A discussão problematizada pode permitir que essas concepções emerjam. De outro lado, a problematização poderá permitir que o aluno sinta necessidade de adquirir outros conhecimentos que ainda não detém; ou seja, coloca-se para ele um problema para ser resolvido. Eis por que as questões e situações devem ser problematizadas." (Delizoicov e Angotti, 20001; apud Ferrari, 2008 p. 11-12).

Neste âmbito segundo Honorato e Mion (2009, p. 2), Bachelard propõe que sejam formuladas questões em que os educandos busquem solucionar os problemas propostos, incentivando ao ato de desenvolver o conhecimento científico:

"A problematização é imprescindível na construção do conhecimento científico. O espírito científico pode construir respostas para as perguntas à medida que é problematizado. A elaboração dessa resposta insere o sujeito em um processo de pesquisa no qual ele percorre um longo caminho para construir o conhecimento científico que requer a ruptura com os conhecimentos iniciais resultantes das interações cotidianas do sujeito com sua realidade concreta." (Bachelard, 1996²; apud Honorato e Mion, 2009, p. 2).

A experimentação segundo a técnica de problemas proposta por Henning (1986) contempla a experimentação por parte dos estudantes, para que suas hipóteses sejam confirmadas ou não:

"Experimentação: Esta atividade de comprovação ou negação experimental (empirismo) da(s) hipóteses(s) formuladas(s) e requer reflexão e planejamento das tarefas e organização dos materiais s serem utilizados. É fundamental que as tarefas sejam idealizadas e executadas pelo aluno e sempre em relação ao

\footnotetext{
${ }^{1}$ Delizoicov, D. e Angotti, J. A. P.. Metodologia do ensino de ciências. São Paulo, Cortez, 2000.

${ }^{2}$ Bacharelard, G.. A formação do espírito científico. Rio de Janeiro, Contraponto, 1996.
} 
problema a ser resolvido e à(s) hipóteses em exame(s)." (Henning, 1986, $p$. 255).

Tomando como base o que foi exposto, o presente trabalho refere-se ao desenvolvimento de uma atividade experimental planejada e elaborada em conjunto com os integrantes do Clube de Ciências da Escola Estadual João Negrão, localizada na Cidade de Teixeira Soares - PR, vinculado ao Projeto Criação de Clube de Ciências proposto pela Universidade Estadual de Ponta Grossa (UEPG) por meio do Programa Universidade Sem Fronteiras - Secretaria de Educação do Estado do Paraná e com a participação de acadêmicos das Licenciaturas em Física e Química e professores do departamento de física da UEPG.

\section{Metodologia}

A proposta metodológica utilizada neste trabalho está fundamentada nas ideias de Paulo Freire, essencialmente no que diz respeito à aprendizagem a partir daquilo que o aprendiz já sabe buscando-se estabelecer uma relação com sua realidade e com seus interesses. Do ponto de vista psicológico, o trabalho baseou-se na teoria de aprendizagem significativa de Ausubel e nos trabalhos de Moreira para quem a aprendizagem significativa crítica permite ao sujeito fazer parte de sua cultura ao mesmo tempo em que se utiliza da informação, da tecnologia e da ciência sem ser dominado pelas mesmas. Neste sentido é que se buscou estabelecer como meta para os estudantes participantes do Projeto Criação de Clubes de Ciências a compreensão de como é construído o conhecimento científico.

Tendo por base os pressupostos acima a realização de encontros semanais com os estudantes associados ao Clube de Ciências permitiu a escolha do tema problematizador, que surgiu do interesse dos mesmos em investigar e aprender. A incentivação ocorreu por meio de diálogo, onde o monitor propôs inicialmente que os estudantes observassem fenômenos relacionados ao tema problematizador.

Na sequencia procedeu-se a etapa de problematização, como resultado das observações do cotidiano vivenciadas pelos estudantes. Logo após a formulação destas indagações os estudantes foram orientados a tentar respondê-las sem consultar qualquer bibliografia. A intenção desta dinâmica de grupo foi formular hipóteses utilizando o conhecimento prévio - derivado se seu conhecimento anterior contemplando formulação científica, senso comum ou concepção espontânea - de modo a levantar subsídios do conhecimento prévio sobre o tema abordado. Ao final da etapa de problematização, os estudantes iniciaram "uma pesquisa" - isto é, uma busca pelos assuntos levantados na problematização, respondendo desta forma suas questões e confrontando suas hipóteses. 
Finalizada a etapa da problematização, surgiu a necessidade e interesse em planejar e elaborar uma atividade experimental que relacionasse isolantes e condutores térmicos. Para sua execução os estudantes foram divididos em grupos de três integrantes. Para cada grupo foi definido um relator, um produtor e um apresentador. O relator tinha como responsabilidade anotar todas as questões levantadas pelos participantes durante o experimento. $O$ produtor em preparar o material para execução da atividade e o apresentador em apresentar os resultados obtidos em um próximo encontro, com a participação dos demais grupos.

A atividade experimental teve como objetivo fornecer condições para os que estudantes verificassem a validade de suas hipóteses por meio de resultados mensuráveis obtidos por meio da experimentação. Buscando organizar o ambiente e o procedimento experimental, foi elaborado um roteiro, de forma a ajudar na coleta de dados e direcionar as observações realizadas pelos estudantes. Os materiais separados para o estudo foram escolhidos pelos estudantes de acordo com o interesse e levando-se em conta as questões cotidianas observadas e problematizadas inicialmente.

Abaixo, apresenta-se o roteiro da atividade experimental proposto pelos estudantes em conjunto com os monitores.

Título:

Condutores e Isolantes Térmicos

Objetivos:

-Observar o fenômeno de condução de calor em diferentes materiais.

- Identificar os materiais condutores e isolantes térmicos por meio da análise da diferença de temperatura e de tempo cronometrado.

Material:

Uma barra de plástico rígido (régua escolar), um pedaço de madeira, uma barra de alumínio, uma barra de ferro, um pedaço de borracha de pneu, uma placa de vidro, uma barra de isopor, um pedaço de telha de amianto, uma barra de cobre, uma tira de caixa de leite. Todos os materiais (figura 1) com aproximadamente as mesmas dimensões $(6 \mathrm{~cm} \times 30 \mathrm{~cm}$ ). Um suporte para fixar as barras, uma vela, cronômetro digital, termômetro e percevejos. 


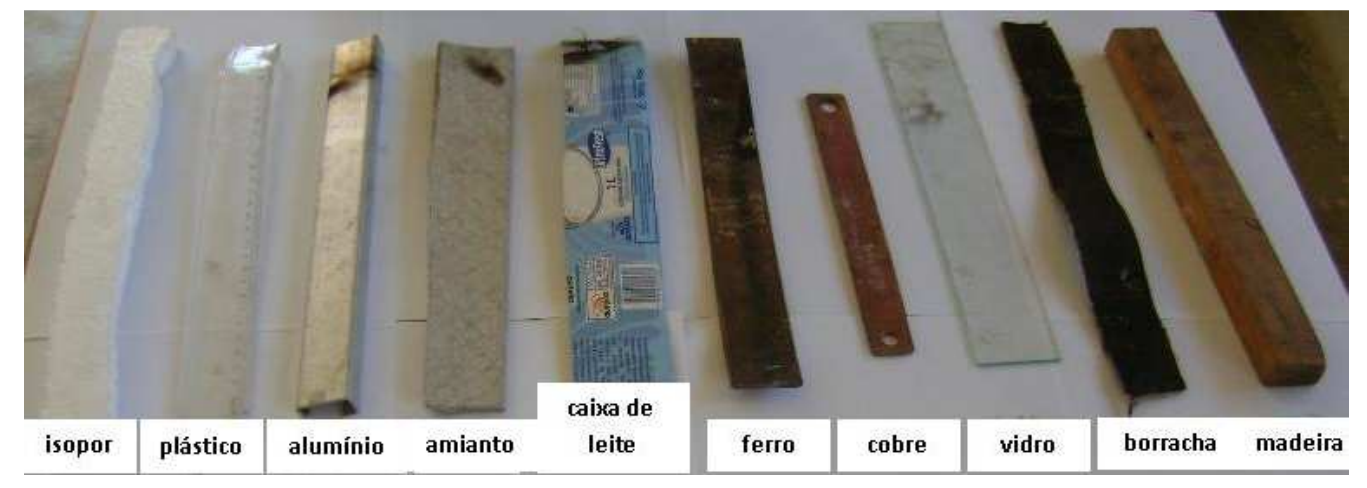

Figura 1 -Diferentes materiais utilizados na atividade experimental de condutores e isolantes térmicos.

\section{Procedimento Experimental:}

1. Deixar um espaço inicial de $10 \mathrm{~cm}$, conforme mostra a figura abaixo:

\section{O}

Figura 2 - Esquema da disposição do percevejo nas barras de diferentes materiais

2. Derreter gotas de vela sobre cada barra (nos diferentes materiais - figura 1 e conforme a figura 2) aderindo o percevejo sobre as gotas (colocar a cabeça do percevejo grudada sobre o pingo de vela);

3. Colocar uma barra de cada vez sobre o suporte, deixando o espaço de $10 \mathrm{~cm}$ livre em uma das extremidades;

4. Acender a vela abaixo deste espaçamento, mantendo a chama da vela fora de contato com a superfície da barra (figura 3);

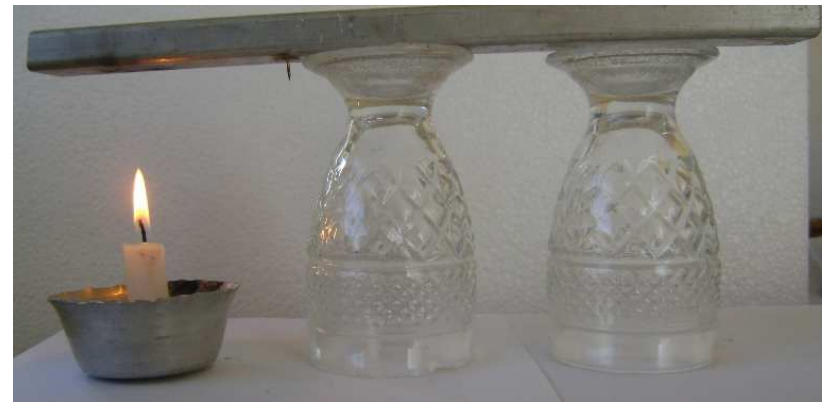

Figura 3 - Barra de alumínio submetido ao aquecimento da chama de uma vela. Após algum tempo o percevejo se desprende da barra.

5. Usar o termômetro para medir a temperatura inicial $T_{o}$ da barra. 
6. Cronometrar o tempo a partir do momento em que a vela é posicionada abaixo do material a ser submetido ao aquecimento e a cada percevejo que desprender reiniciar a contagem no cronômetro.

7. Depois que o percevejo se desprender, medir a temperatura final $T$ da barra usando como referência o centro da barra (figura 4).

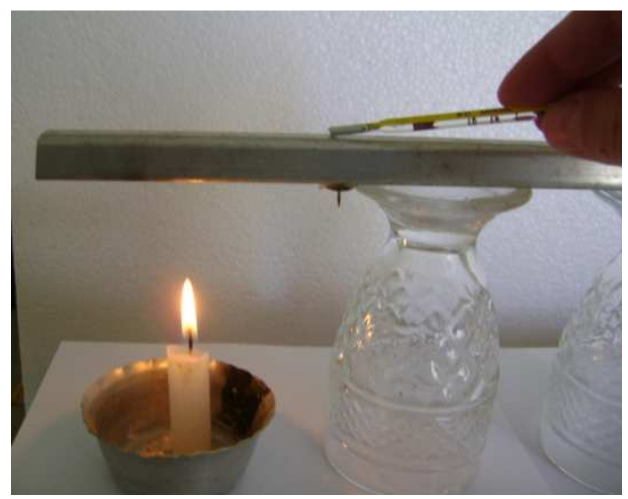

Figura 4 - Local da medição da temperatura final a qual é realizada logo que o percevejo desprende da barra.

8. Anotar os tempos e as temperaturas na tabela 1 abaixo.

Tabela 1 - Coleta de dados da atividade experimental de condutividade térmica

\begin{tabular}{|c|c|c|c|}
\hline Material (barra) & Tempo & $T_{o}\left({ }^{\circ} \mathrm{C}\right)$ & $T\left({ }^{\circ} \mathrm{C}\right)$ \\
\hline \multicolumn{4}{|l|}{ plástico } \\
\hline \multicolumn{4}{|l|}{ madeira } \\
\hline \multicolumn{4}{|l|}{ alumínio } \\
\hline \multicolumn{4}{|l|}{ ferro } \\
\hline \multicolumn{4}{|l|}{ cobre } \\
\hline \multicolumn{4}{|l|}{ amianto } \\
\hline \multicolumn{4}{|l|}{ borracha } \\
\hline \multicolumn{4}{|l|}{ vidro } \\
\hline \multicolumn{4}{|l|}{ caixa de leite } \\
\hline isopor & & & \\
\hline
\end{tabular}

9. Repetir todo o procedimento para cada barra de diferentes materiais.

10. Em qual dos materiais o percevejo se desprendeu mais rapidamente? Que temperatura esse material atingiu? Ele é um bom ou um mau condutor de calor? 
11. Em qual dos materiais o percevejo se desprendeu mais lentamente? Que temperatura esse material atingiu? Ele é um bom ou um mau condutor de calor?

12. A diferença de temperatura entre os materiais foi diferente ao final de cada amostragem?

13. Ordene os materiais de forma que o melhor condutor esteja no topo da tabela.

14. Separe um dos "melhores condutores" definido pela equipe e verifique qual é a sua temperatura ambiente To.

15. Agora coloque novamente este sobre o suporte e ascenda a vela.

16. Coloque a barra de isopor sobre este e utilize o termômetro ou o próprio tato para verificar se o calor passa através da barra de isopor que deverá estar sobreposta sobre a barra (figura 5) do "melhor condutor" selecionado pela equipe.

17. Que temperatura atingiu a barra de isopor? Ficou quente ou frio? A que conclusão vocês chegaram?

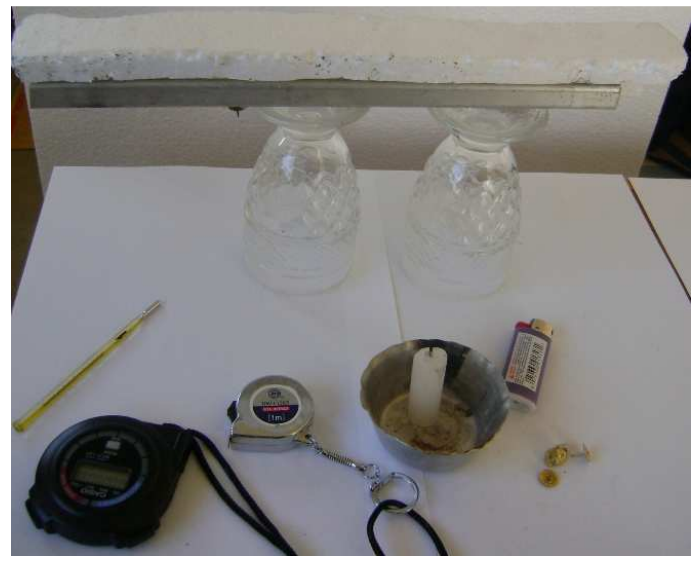

Figura 5 - Esquema montado para realização da atividade experimental conforme itens 14, 15, 16 e 17 do roteiro experimental.

\section{Resultados e Discussão}

A partir da observação inicial de fenômenos relacionados a frio e quente e sendo este um tema bastante abrangente, muitas questões foram elaboradas por meio de exemplificações de situações que ocorrem no cotidiano, permitindo direcionar as questões ao tema condutores e isolantes.

A seguir, apresentam-se os questionamentos elaborados pelos estudantes a partir da problematização inicial: 
Porque (sic) as caixas de leite longa vida são mantidas em locais não refrigerados no supermercado, sem que isto afete a qualidade do leite?

Porque (sic) as janelas, ou qualquer outro objeto feito de metal ou ferro quando expostas ao sol (sic) durante um dia inteiro ficam muito mais quentes que um banco de madeira?

E o porquê (sic) no inverno estes mesmos objetos feitos de metal são muito mais geladas que o plástico?

Como uma caixa de isopor consegue manter a água no estado sólido?

Porque (sic) as casas de madeira são mais aconchegantes no inverno que as de alvenaria?

Porque (sic) locais com telhado feito com telha de barro é (sic) mais fresco que casas com telhado de amianto?

Como que o vidro da janela não esquenta sendo que a janela (parte metálica) fica quente ao estar o dia todo exposto ao sol (sic)?

Porque (sic) dizemos que a borracha é um bom isolante?

Um martelo, por exemplo: tem o cabo de madeira e a "cabeça" de ferro como pode a parte de ferro ser mais fria que o cabo de madeira sendo que os dois estão na mesma temperatura ambiente? É o mesmo que acontece com os talheres da cozinha?

Porque (sic) $100 \mathrm{ml}$ (sic) de água esquentam mais rapidamente que 1 litro de água se a quantidade de calor que sai da boca do fogão é igual?

Após a formulação destas questões os estudantes levantaram as hipóteses para cada questão tomando com base seus conhecimentos prévios e que apresentadas a seguir:

O papel não permite que o leite esquente e o alumínio serve como revestimento para que o papel não derreta.

Se os dois ficarem o mesmo tempo expostos ao sol (sic) o metal absorverá mais calor que a madeira e por isso ficará mais quente.

$O$ isopor é um isolante térmico e não permite que o calor externo afete dentro da caixa, por isso o gelo não derrete rapidamente.

O tijolo (cerâmica) é mais frio que a madeira e por isso as casas de madeira são mais quentes no inverno. 
O vidro é transparente então não absorve calor enquanto que a parte de metal de uma janela absorve calor.

A borracha é um isolante porque se estivermos com sapatos de borracha não levamos choque, ela não conduz eletricidade.

A madeira é um isolante térmico enquanto que o metal é um condutor.

Porque quanto menor a massa menos tempo leva para aquecer.

A pesquisa bibliográfica possibilitou que os estudantes levantassem novas questões gerando assim uma nova formulação de suas hipóteses, agora com o embasamento teórico necessário para uma possível explicação científica às suas questões e que estão indicadas a seguir:

O alumínio é um bom condutor de calor, mas o papel é um bom isolante, assim o papel não deixa com que aconteça troca de calor com o ambiente conservando o leite na caixa longa vida. Após aberto devemos manter refrigerado porque ocorrerá troca de calor com o ambiente. No caso de uma caixa de isopor, é mesma coisa. O isopor é um bom isolante térmico assim não permite que ocorra troca de calor com o ambiente, impossibilitando o gelo derreter.

O calor específico do ferro é menor que o calor específico da madeira ou do plástico. Assim se os dois corpos tiverem as mesmas massas e receberem durante o dia a mesma quantidade de calor (do Sol) o metal irá ficar com maior temperatura (mais quente). À noite, quando estiver mais frio o metal irá esfriar mais rapidamente que a madeira. Isso explica também o porquê as casas (sic) de madeira são mais aconchegantes que as de alvenaria (tijolo). A eternite (sic) é feita de amianto e o amianto possui uma condutividade térmica menor que a do tijolo assim quando o sol (sic) fornece calor ela esquenta mais rapidamente que as telhas, por isso as casas com telhas são mais frescas que as com telha de amianto.

O calor específico do vidro é maior que o calor específico do ferro da janela assim o ferro aquece mais que o vidro.

A borracha é um bom isolante térmico e, bons isolantes térmicos, são também bons dielétricos (isolantes) de eletricidade.

Quando fornecemos a mesma quantidade de calor para quantidades diferentes de água a variação de temperatura será diferente. 
A procura por respostas e a reformulação das hipóteses proporcionou aos estudantes maior interesse e consequentemente o aprendizado do tema proposto inicialmente: condutores e isolantes térmicos. Os estudantes perceberam que não existe um único fator responsável para a determinação das características de materiais isolantes e condutores de calor.

Na finalização de suas atividades os estudantes relataram que não tinham conhecimento suficiente para responder suas questões iniciais e que não esperavam a existência de diversos fatores envolvidos no estudo dos materiais e assim como o que determina capacidade de conduzir ou não calor, concluindo que:

Podemos aquecer um mesmo tipo de material, cada um recebendo uma quantidade igual de calor, mas se as massas forem diferentes a capacidade térmica desse material será diferente. $O$ coeficiente de condutividade térmica relaciona a quantidade de calor recebida pelo corpo, suas dimensões e ainda, do tempo que leva para essa quantidade de calor percorrer o material.

Durante a atividade experimental os estudantes tomaram nota dos dados, fizeram observações e montaram a tabela abaixo conforme os itens $10,11,12$ e 13 do procedimento experimental e que á apresentada na Tabela 2. 
Tabela 2 - Dados coletados, analisados e coletados pelos estudantes da atividade experimental de condutividade térmica. ( $T_{0}$ é a temperatura ambiente).

\begin{tabular}{|c|c|c|c|c|c|c|}
\hline & Grupo 01 & & & Grupo 02 & & \\
\hline $\begin{array}{l}\text { Material } \\
\text { da barra }\end{array}$ & Tempo & $\begin{array}{l}T_{o} \\
\left({ }^{\circ} \mathrm{C}\right)\end{array}$ & $\begin{array}{l}T \\
\left({ }^{\circ} \mathrm{C}\right)\end{array}$ & Tempo & $\begin{array}{l}T_{o} \\
\left({ }^{\circ} \mathrm{C}\right)\end{array}$ & $\begin{array}{l}T \\
\left({ }^{\circ} \mathrm{C}\right)\end{array}$ \\
\hline Cobre & $3 \mathrm{~min}$ & 19 & 65 & $3,5 \mathrm{~min}$ & 19 & 64 \\
\hline alumínio & $4 \min$ & 19 & 56 & $5 \min$ & 19 & 58 \\
\hline Ferro & $6 \min$ & 19 & 54 & $5 \mathrm{~min}$ & 19 & 56 \\
\hline Vidro & $\begin{array}{l}\text { a partir dos } 6 \text { min o vidro } \\
\text { estourou impossibilitando } \\
\text { o desprendimento do } \\
\text { percevejo }\end{array}$ & 16 & $40^{\circ}$ & $\begin{array}{l}\text { não foi possível derreter a } \\
\text { parafina, pois o vidro } \\
\text { quebrou antes disso } \\
\text { acontecer }\end{array}$ & 16 & 44 \\
\hline plástico & $\begin{array}{l}\text { a partir de } 2 \text { min. o } \\
\text { plástico começou a } \\
\text { derreter o que } \\
\text { impossibilitou o } \\
\text { desprendimento do } \\
\text { percevejo. }\end{array}$ & 17 & 42 & $\begin{array}{l}\text { não foi possível coletar o } \\
\text { tempo, pois o plástico } \\
\text { derreteu antes da } \\
\text { parafina derreter. }\end{array}$ & 17 & 40 \\
\hline madeira & $\begin{array}{l}7 \text { min e não derreteu a } \\
\text { parafina }\end{array}$ & 18 & 37 & $\begin{array}{l}8 \text { min, não derreteu a } \\
\text { parafina }\end{array}$ & 18 & 38 \\
\hline borracha & $\begin{array}{l}\text { submetido ao } \\
\text { aquecimento durante } 14 \\
\text { min, mas a parafina não } \\
\text { derreteu. }\end{array}$ & 16 & 23 & $\begin{array}{l}\text { não derreteu a parafina } \\
\text { deixamos por } 10 \mathrm{~min} \text {. }\end{array}$ & 17 & 23 \\
\hline cerâmica & $\begin{array}{l}\text { foi aquecido durante } 12 \\
\text { min, mas não derreteu a } \\
\text { parafina. }\end{array}$ & $17^{\circ}$ & 23 & $\begin{array}{l}\text { Deixamos sob a vela } \\
\text { durante } 10 \text { min, mas não } \\
\text { descolou o percevejo. }\end{array}$ & $17^{\circ}$ & 22 \\
\hline amianto & $\begin{array}{l}15 \text { min e não derreteu a } \\
\text { parafina }\end{array}$ & 17 & 22 & $\begin{array}{l}12 \text { min, mas não } \\
\text { desgrudou o percevejo. }\end{array}$ & 17 & $21^{\circ}$ \\
\hline $\begin{array}{l}\text { caixa de } \\
\text { leite }\end{array}$ & $\begin{array}{l}\text { foi deixado até } 12 \text { min, } \\
\text { porém queimou o } \\
\text { papelão mas o } \\
\text { revestimento de alumínio } \\
\text { não queimou. Não } \\
\text { derreteu a parafina. }\end{array}$ & 17 & 22 & $\begin{array}{l}10 \text { min, porém não houve } \\
\text { o desprendimento do } \\
\text { percevejo. }\end{array}$ & 16 & 21 \\
\hline
\end{tabular}

A análise dos dados realizada pelos estudantes possibilitou a definição de um critério na determinação do melhor condutor de calor. Ou seja, a temperatura final mais elevada atingida em menos tempo. Nos materiais em que o desprendimento do percevejo não foi possível visualizar, a equipe reorganizou a tabela de acordo com a temperatura final mais elevada. Esse critério adotado indica que os estudantes perceberam que quanto menor o tempo para o derretimento da parafina e quanto maior for a temperatura final local, maior é o coeficiente de condutividade térmica. 
Após o preenchimento da tabela os estudantes foram incentivados a pesquisar na biblioteca o coeficiente de condutividade térmica teórica dos materiais analisados. Como resultado final constatou-se que a ordem como classificaram (ordem crescente do tempo de derretimento da parafina) em sua atividade estava de acordo com a encontrada nas referências bibliográficas.

Alguns materiais não suportaram o aquecimento aplicado, como foi o caso do vidro comum, com isto os estudantes levantaram a importante questão: "a fonte de calor estava muito próxima, pois o vidro quebrou (estourou) exatamente no local onde a chama foi disposta." Isto proporcionou uma discussão interessante que acontece nos incêndios onde a temperatura é muito elevada e os vidros não suportando o aquecimento "estouram". Isto ocorre até com os vidros temperados.

Quando a barra de alumínio, identificada como o melhor condutor, foi novamente submetida a aquecimento (itens 14, 15, 16 e 17 do roteiro experimental) e colocado sobre ela a barra de isopor. A temperatura do isopor foi verificada pelos estudantes por meio do tato e apesar do alumínio atingir uma temperatura bastante elevada percebeu-se que o isopor não se aquece, o que comprova a capacidade de condutividade térmica muito pequena do isopor. Com isso os estudantes identificaram a possibilidade de revestir um bom condutor térmico com um bom isolante térmico a fim de não haver fluxo de calor para o ambiente em que o isopor se encontra ou deste para o material sendo aquecido ou resfriado.

\section{Conclusão}

A execução deste trabalho que teve por base as ideias de Paulo Freire, de Ausubel e de Moreira, possibilitou que os estudantes utilizassem seus conhecimentos prévios de modo a estabelecer uma relação com sua realidade e com seus interesses, além de propiciar oportunidade para que os estudantes vivenciassem experiências nas quais Ihes permitiram compreender que ao mesmo tempo em que se utiliza da informação, da tecnologia e da ciência pode-se refletir sobre como é construído o conhecimento científico e quais são as possíveis implicações resultantes de tal atividade sobre nossas vidas.

A análise dos resultados obtidos considerando as respostas dos estudantes que participaram das atividades nos permite estabelecer como conclusões principais o que segue:

i. A problematização inicial partindo dos próprios dos estudantes contribui significativamente no que diz respeito ao ensino e aprendizagem;

ii. As atividades desenvolvidas aplicando-se a técnica da problematização, a pesquisa em referências bibliográficas, a formulação de hipóteses e a experimentação 
(empirismo); planejadas e elaboradas com a participação dos grupos resultou em envolvimento e comprometimento na busca da aquisição do conhecimento científico por parte dos estudantes;

iii. Os principais veículos para a busca individual e em grupo da aprendizagem são o interesse e a curiosidade e que tem relação direta com os conhecimentos que o individuo já domina bem como dos usos socioculturais que faz deles;

iv. Quando os estudantes são instigados a buscar informação, conceitos e teorias para responder suas próprias perguntas, tornam-se apreciadores dos livros e interessados em temas abordados nas Ciências Naturais;

v. Ao se colocar em análise situações do cotidiano vivenciadas pelos estudantes, propiciam-se condições para que eles as aproximem de sua realidade, conectando-a, com as informações contidas nos livros, as quais muitas vezes são ignoradas por se apresentarem de maneira complexa ou em uma linguagem sobre a qual em geral não tem domínio;

vi. Este trabalho permitiu a possibilidade de ensinar conteúdos das Ciências Naturais, neste caso relacionados à Física, por meio do método científico o que pode levar ao domínio crítico da linguagem científica;

vii. As atividades desenvolvidas possibilitaram uma participação ativa de estudantes interessados em resolver situações problemas de modo que fossem "pensadas" por meio da linguagem científica.

\section{Agradecimentos}

Agradecemos o apoio da direção da Escola Estadual João Negrão, localizada na Cidade de Teixeira Soares - PR, e da SETi / através do Programa Universidade Sem Fronteiras.

\section{Referências}

Ausubel, D. P.. Educational Psychology: a Cognitive view. Nova York, Holt, Rinehart and Winton, 1968.

de Souza, O., Gregorio-Hetem, J. e Amon, M.C. I.. Atividades práticas do projeto telescópios na escola: processos de aprendizagem. In: VII ENPEC - Encontro Nacional de Pesquisa em Educação em Ciência, novembro de 2009, Florianópolis. Anais do VII ENPEC, Florianópolis, ABRAPEC, nov. 2009. 13p. Disponível em: <http://www.fae.ufmg.br/abrapec/viempec/7enpec/pdfs/620.pdf> Acesso em: 10 nov. 2010. 
Espíndola, K. e Moreira, M. A.. Relato de uma experiência didática: ensinar física com os projetos didáticos na eja, estudo de um caso. Experiências em Ensino de Ciências, Porto Alegre, V1(1), pp. 55-66, 2006.

Ferrari, P. C.. Temas contemporâneos na formação docente à distância - uma introdução à teoria do caos. 2008. 135f. Tese (Doutorado em Educação Científica e Tecnológica). Centro de Educação da Universidade Federal de Santa Catarina. Florianópolis, 2008.

Freire, P.. Pedagogia do Oprimido. 29a ed.. Rio de Janeiro. Paz e terra, 1987.

Henning, G. J.. Metodologia do ensino de ciências. 3a ed.. Porto Alegre, Mercado Aberto, 1986.

Honorato, M. A. e Mion, R. A.. A importância da Problematização na Construção e na Aquisição do Conhecimento Científico pelo Sujeito. In: VII ENPEC - Encontro Nacional de Pesquisa em Educação em Ciência, novembro 2009, Florianópolis. Anais do VII ENPEC, Florianópolis, ABRAPEC, nov. 2009. 12p. Disponível em:

<http://www.fae.ufmg.br/abrapec/viempec/7enpec/pdfs/874.pdf> Acesso em: 10 de nov. 2010 Krummenauer, W. L.; da Costa, S.S. C. e da Silveira, F. L.. Uma experiência de ensino de física contextualizada para a educação de jovens e adultos. Rev. Ensaio, Belo Horizonte, v. 12, n. 02, p.69-82, mai-ago 2010.

Moreira, M.A.. Teorias de aprendizagem. São Paulo, Editora Pedagógica Universitária, 1999. 195 p.

Moreira, M.A.. Aprendizagem significativa crítica. Porto Alegre, IFUFRGS, 2010. 24p.. Disponível em: < http://www.if.ufrgs.br/ moreira/apsigcritport.pdf> Acesso em: 10 de nov. 2010 .

Nascimento, T. G. e Rezende Junior, M. F.. A produção sobre divulgação científica na área de educação em ciências: referenciais teóricos e principais temáticas. Investigações em Ensino de Ciências, Porto Alegre, V15(1), pp. 97-120, 2010.

Rosa, P. R. da S.. Fatores que influenciam o ensino de ciências e suas implicações sobre os curricula dos cursos de formação de professores. Caderno Catarinense de Ensino Física, Florianópolis, v. 16, n. 3: p. 287-313, dez. 1999. 
Sabrina Passoni. Acadêmica Licenciatura em Física - Universidade Estadual de Ponta Grossa e Bolsista do Programa Universidade sem Fronteiras. sabrinapassoni@hotmail.com

Nadiangela Mayer. Acadêmica Licenciatura em Física - Universidade Estadual de Ponta Grossa e Bolsista do Programa Universidade sem Fronteiras. nadimayer@hotmail.com

Jeremias Borges da Silva. Pesquisador e professor do Departamento de Física da Universidade Estadual de Ponta Grossa.silvajb@uepg.br

André Maurício Brinatti. Pesquisador e professor do Departamento de Física da Universidade Estadual de Ponta Grossa. brinatti@uepg.br

Silvio Luiz Rutz da Silva. Pesquisador e professor do Departamento de Física da Universidade Estadual de Ponta Grossa.rutz@uepg.br 